\title{
Experimental Study of Long-Wave Night Sky Radiation in Owerri, Nigeria for Passive Cooling Application
}

\author{
N. V. Ogueke ${ }^{1, *}$, C. C. Onwuachu ${ }^{1}$ and E. E. Anyanwu ${ }^{1}$ \\ ${ }^{1}$ Mechanical Engineering Department, Federal University of Technology, P.M.B. 1526, Owerri, Nigeria. \\ * Corresponding author. Tel: +234 802540 5757, E-mail: nvogueke@yahoo.co.uk
}

\begin{abstract}
An experimental study to determine the net flux of long wave radiation from the earth's surface to the atmosphere in Owerri, south east Nigeria for passive cooling applications is presented. The values of the effective sky temperatures are also determined. The experimental rig which is a thermal radiator consists of a flat mild steel plate of dimensions $152.2 \mathrm{~cm} \mathrm{x} 38.1 \mathrm{~cm}$ x $0.3 \mathrm{~cm}$ coated with high emissivity black paint. A copper tube was used to form five turns and then soldered to the steel plate. Water from a well insulated tank placed at about $0.8 \mathrm{~m}$ above the surface of the thermal radiator flowed through the radiator. Thermocouples were strategically inserted on the radiator assembly to measure the plate temperature and water temperature as it flowed along the copper tube. The tests were conducted under the meteorological conditions of Federal University of Technology, Owerri for the period covering March to May; a period often free from the harmattan dust haze. The results revealed that a net long-wave nocturnal cooling power of $66.1 \mathrm{~W} / \mathrm{m}^{2}$ is possible. These results are in the same order of magnitude with those obtained elsewhere with similar climatic condition as Owerri, Nigeria.
\end{abstract}

Keywords: Nocturnal cooling, Experimental, Long wave, Passive cooling, Radiation

\section{Nomenclature}

$A_{p} \quad$ Plate area ................................m

$C_{\text {water }} \quad$ Specific heat capacity of water...J $/ \mathrm{kgK}$

$F_{p} \quad$ Plate view factor

$h \quad$ Convection heat transfer coefficient between air and plate .............W/ $\mathrm{m}^{2} \mathrm{~K}$

$T_{\text {out }} \quad$ Outlet water temperature....................

$T_{p} \quad$ Plate temperature ........................

$T_{p w b} \quad$ Temperature of the underside of

$\dot{m}_{\text {water }}$ Mass flow rate of water ............ kg/s

$q_{\text {net }} \quad$ Net outgoing radiation ..............W/ $/ \mathrm{m}^{2}$

$T_{\text {sky }} \quad$ Sky temperature ..........................

$Q_{\text {cond }} \quad$ Heat transferred by conduction.......W

$U_{\text {ins }} \quad$ Overall heat transfer coefficient of the combined plywood and cotton wool

$Q_{\text {conv }}$ Heat transferred by natural convection

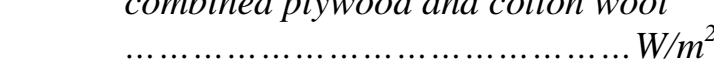

$Q_{n e t} \quad$ Net thermal radiation from plate ......W

$Q_{\text {water }}$ Heat transferred from water ...........W

$T_{\text {amb }} \quad$ Ambient temperature .....................

$T_{\text {in }} \quad$ Water inlet temperature..................

$\begin{array}{ll}\varphi_{d} & \text { Downwards radiation .............W/ } / m^{2} \\ \varphi_{u} & \text { Upward radiation ..................W/ } / m^{2} \\ \varepsilon_{p} & \text { Emissivity of plate } \\ \sigma & \text { Stefan-Boltzmann constant ....W } / \mathrm{m}^{2} K^{4}\end{array}$

\section{Introduction}

There is a growing demand for space cooling in hot climates resulting from increasingly harsher climatic conditions as a result of global warming and climate change. This has resulted to an increase in demand for grid connected electrical energy, hence reducing the available energy for other services. Countries with such climates like Nigeria therefore face serious peak energy demand problems. Interestingly, the sky is known to be very cold and as such it can be used as a heat sink for radiating bodies on the earth's surface. This is because the atmospheric temperature decreases with elevation and the atmosphere is partly transparent to some radiation within the infrared region of the spectrum. This concept, which requires a good knowledge of atmospheric radiation flux at the earth's surface, if effectively harnessed could be used significantly to reduce the demand placed on grid connected electricity from air conditioning as well as reduce the energy bills resulting from it. Apart from air condition for comfort, it can also be used for agricultural studies and solar collector analysis [1]. 
Ordinarily if the emitted radiation from a surface exceeds its absorbed radiation, cooling will result. Thus it is possible to cool hotter surfaces and objects on the ground by radiation to the night sky; a concept called nocturnal (night sky) radiation. The cooling resulting from it is called radiative cooling. Rate and degree of radiative cooling achieved depend on the intensity of the nocturnal radiation. Many factor affect nocturnal radiation intensity; they include weather condition as well as the nature of the radiating surface. Some works have been reported on efforts to measure nocturnal radiation intensity in different locations. Angstrom [2] and Maurer [3] investigated the nocturnal cooling of bodies exposed to the sky, Ezekwe [1] carried out nocturnal radiation measurements in Nsukka, Nigeria while Armenta-Déu et al [4] carried out a thermal analysis of a prototype to determine radiative cooling thermal balance. More recently, knowledge of availability of nocturnal radiation in some regions have been used to design and construct nocturnal radiators for space cooling. These include the works of Cheikh and Bouchair [5], Khedari et al [6], Bagiorgas and Mihalakakou [7] and Dimoudi and Androutsopoulos [8]. Results obtained from these indicate the possibility of significant space cooling by effectively harnessing the nocturnal radiation available in a particular locality.

This work therefore deals with an experimental investigation of the nocturnal radiation intensity in Owerri, a tropical south eastern town in Nigeria. It has three major seasons in a year (rainy, dry and harmattan seasons) with an average day time temperature for all the seasons being in the range of $31-35^{\circ} \mathrm{C}$. At night these temperatures scarcely come down, especially during the dry seasons, thus there is the need to artificially drop them to fairly comfortable values, particularly within a building envelope.

\section{Description of the Thermal Radiator.}

The experimental rig is a thermal radiator consisting of an unglazed mild steel plate of dimensions $152.20 \mathrm{~cm}$ x $38.10 \mathrm{~cm}$ x $3.30 \mathrm{~cm}$. Copper tube of outer diameter $12.20 \mathrm{~cm}$ was curled into five equal turns covering the plate area and then soldered to the mild steel plate such that a perfect thermal contact was achieved between the plate and the tube. The radiator assembly was mounted on a ply wood base $1 \mathrm{~cm}$ thick with an insulation material (cotton wool) $1 \mathrm{~cm}$ thick placed between the thermal radiator and the ply wood base to further reduce heat transfer by conduction. The mild steel plate of the radiator assembly was painted black to increase its emissivity. Water is made to flow through the radiator by gravity by connecting it to a water tank (using an insulated flexible hose) placed on a wooden stand higher than the height of the thermal radiator. Water was continuously circulated through the array of copper tubing. The tank is made of galvanized steel drum and perfectly insulated using fibre glass insulation. The insulation was subsequently wrapped in an aluminium foil; all to reduce heat transfer to the ambient air. Two manual valves were installed on the tank; a wedge valve (inner valve) which was used to start up or stop the process and a parallel gate valve (outer valve) used to control the mass flow rate of water through the thermal radiator assembly. The tank was kept about three metres away from the thermal radiator assembly to avoid obstruction of long-wave radiation. Five K-type thermocouples were inserted at equal distances each on the thermal radiator to measure the temperature of water along the various points on the mild steel plate and hence, determine the average temperature of the radiator. Other parameters monitored are the water tank temperature, ambient temperature and exit water temperature from the thermal radiator. Figs $1 \mathrm{a}$ and $1 \mathrm{~b}$ show the schematic diagram of the thermal radiator and a picture of the experimental rig used for the experiment while Fig. 2 shows the sectional view of the radiator assembly. 


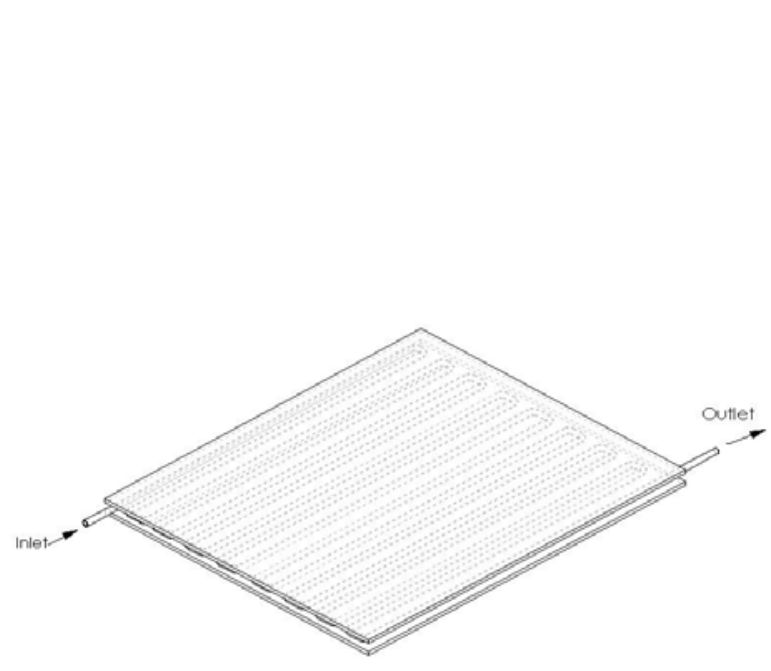

(a)

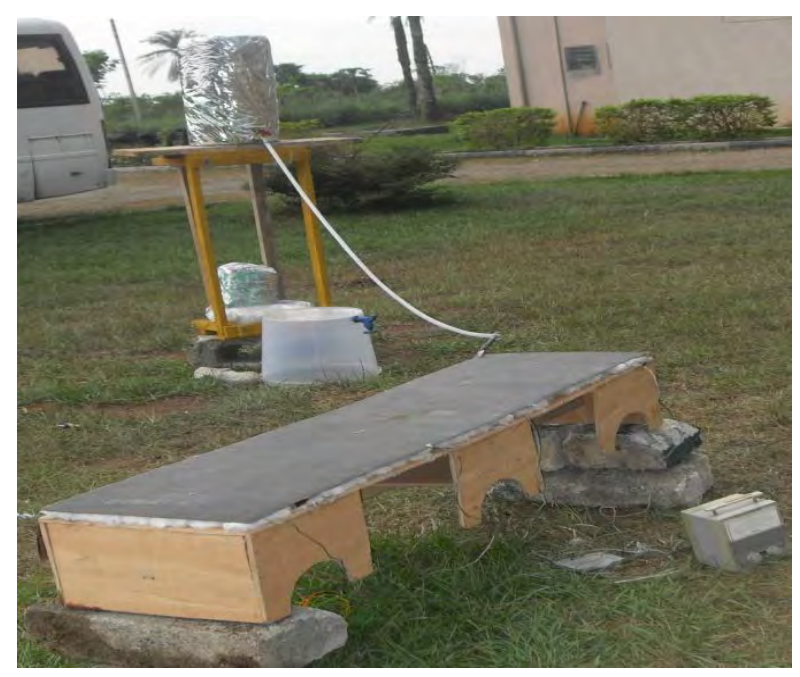

(b)

Fig 1 (a): Schematic diagram of the thermal radiator and (b): the pictorial diagram of the experimental rig.

All dimensions are in $\mathrm{cm}$

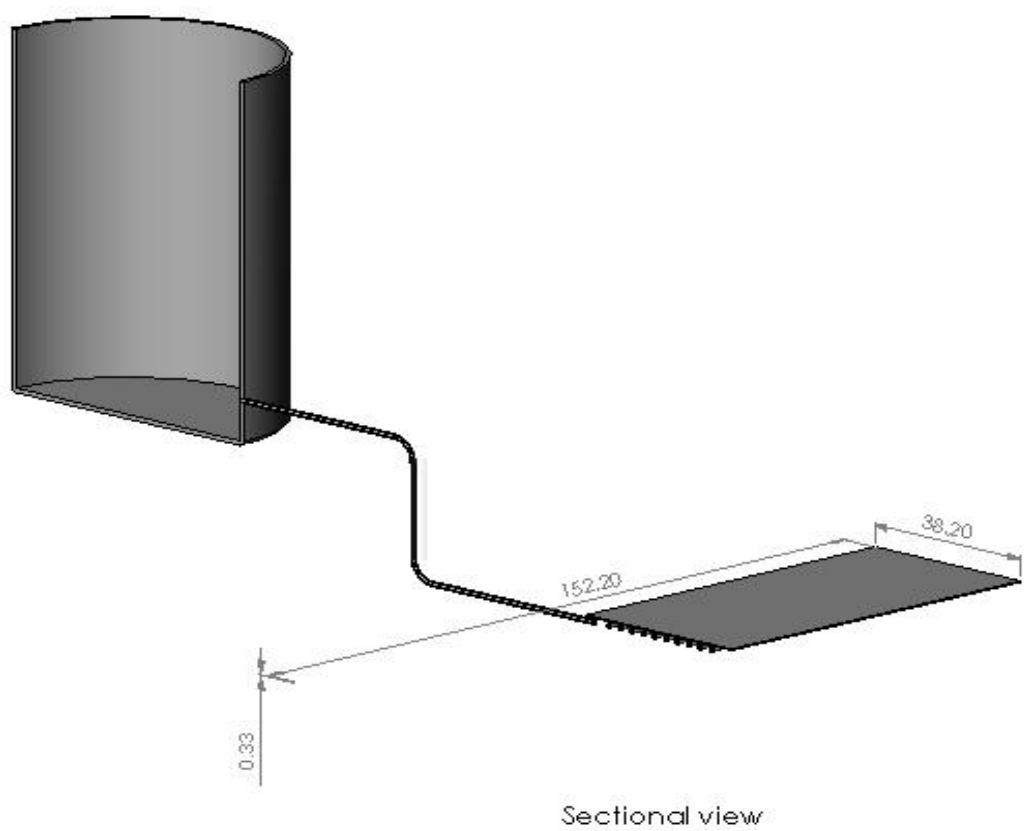

Fig. 2 Sectional view of the radiator assembly

\section{Experimental Tests and Analysis}

Experiments using the thermal radiator were conducted in Owerri, a city in south eastern Nigeria with three major climatic conditions namely; wet, dry and harmattan seasons. During the experimentation, the following parameters were measured: temperature of water at five different points on the mild steel plate, plate temperature, water tank temperature, ambient temperature and exit water temperature from the thermal radiator. The readings were taken at intervals of 30 mins, beginning from 19:00 hrs to 06:00 hrs the following day. These 
temperatures were determined with a K-type thermocouple connected to a 10 - channel Comark electronic thermometer with an accuracy of $\pm 0.1^{\circ} \mathrm{C}$. Data collected were analysed as given below.

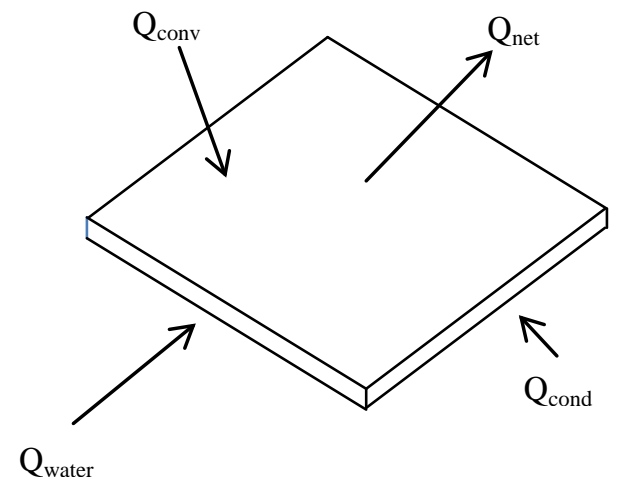

Fig. 3 An energy balance on the nocturnal radiator.

Considering an energy balance on the nocturnal radiator as shown above, the following eqn. (1) results, which enables the determination of the effective sky temperature as well as the downward atmospheric radiation and hence the net outgoing radiation from the plate to the night sky.

$Q_{\text {water }}+Q_{\text {conv }}+Q_{\text {cond }}=Q_{\text {net }}$

$Q_{n e t}$ is the net thermal radiation from the plate to the sky and it is obtained from

$Q_{\text {net }}=\sigma \varepsilon_{p} A_{p} F_{p}\left(T_{p}^{4}-T_{s k y}^{4}\right)$

The heat transferred from the water flowing through the tubes to the plate, $Q_{\text {water }}$ is obtained from eqn. (3) below

$Q_{\text {water }}=\dot{m}_{\text {water }} C_{\text {water }}\left(T_{\text {in }}-T_{\text {out }}\right)$

while the natural convection heat transfer to the plate is obtained from

$Q_{\text {conv }}=h A_{p}\left(T_{a m b}-T_{p}\right)$

The heat transfer by conduction through the plywood and insulation to the plate, $Q_{\text {cond }}$ is obtained from the relation;

$Q_{\text {cond }}=A_{p} U_{\text {ins }}\left(T_{p w b}-T_{p}\right)$

Eqn. (1) was solved using the data collected from various experimental measurements to obtain the only unknown parameter, the effective sky temperature. Assuming the sky to be a black body at an effective temperature $T_{\text {sky, }}$, the downward long-wave sky radiation was computed with the Stefan-Boltzmann law using the sky temperature. This is given as eqn. (6).

$\varphi_{d}=\sigma T_{\text {sky }}^{4}$ 
Similarly, the upward long-wave sky radiation flux was obtained from eqn. (7) by using the ambient air temperature.

$\varphi_{u}=\sigma T_{a m b}^{4}$

Consequently the net outgoing radiation flux from the earth's surface was obtained using eqn. (8) below.

$q_{\text {net }}=\varphi_{u}-\varphi_{d}$

\section{Results and Discussion}

Readings were taken between March and May, a period often free from the harmattan dust haze and enough to give considerable insight into the night sky radiation pattern during the dry season. The month of May however, marks the outset of rainy season. Based on data collected, values of the night sky temperature, downward long wave sky radiation, upward long wave sky radiation and the net long wave sky radiation were determined using eqns. 1, 6-8. Figs. 4 and 5 show the hourly variation of the night sky temperature and its depression below that of the ambient for the dry and rainy seasons while Figs. 6 and 7 show the hourly variation of the upward and downward long wave radiation as well as their net long wave radiation.

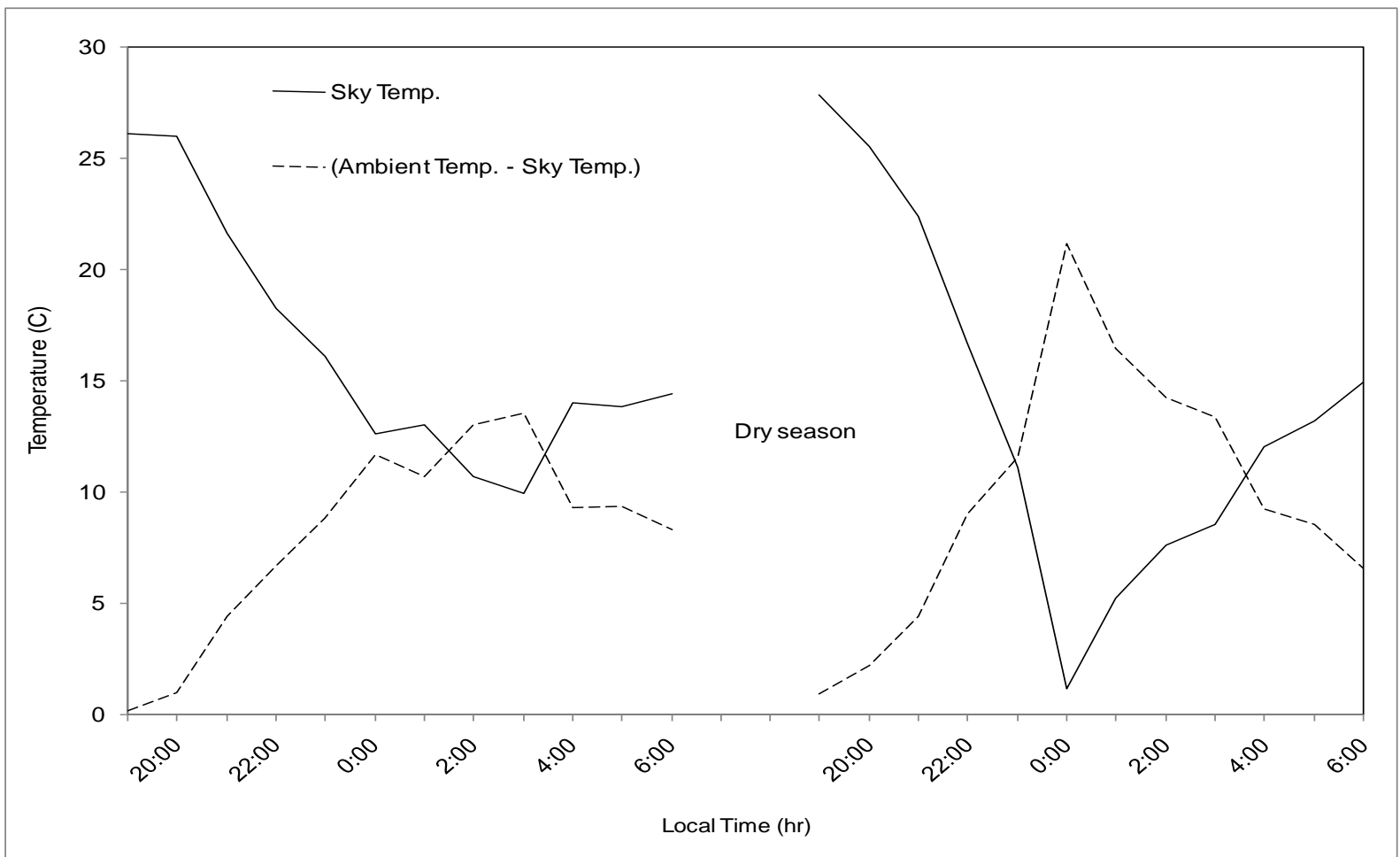

Fig. 4 The night sky temperature and its depression below ambient temperature during the dry season.

It can be seen from these figures that the dry season (characterized by high dry bulb temperature and sometimes a low relative humidity) has lower sky temperatures and higher net long wave radiation than the rainy (wet) season though the variation pattern showed more strong dependence on time of day. The rainy season, with much lower dry bulb temperature and high relative humidity, on the other hand, has more steady sky temperature with a minimum value of about $12^{\circ} \mathrm{C}$. Its net long wave radiation was mostly below $70 \mathrm{~W} / \mathrm{m}^{2}$. These results show that net log wave radiation is higher during the dry than in the rainy season. This may be as a result of a combination of the following factors; clear night sky and lower relative humidity than the rainy season. The rainy season is characterized by overcast sky and high 
relative humidity, hence the lower values recorded. However ambient temperatures are generally lower within this period, thus less cooling is required in order to achieve comfort. In general the net long wave radiation is highest between 22:00 hours - 5:00 hours of the following day with the values ranging between $50-130 \mathrm{~W} / \mathrm{m}^{2}$. These values are well in the same order of magnitude with those obtained for similar climatic conditions and if properly harnessed could provide cooling; enough to provide reasonable comfort during the night times, especially during the dry season when high ambient temperatures make sleeping difficult.

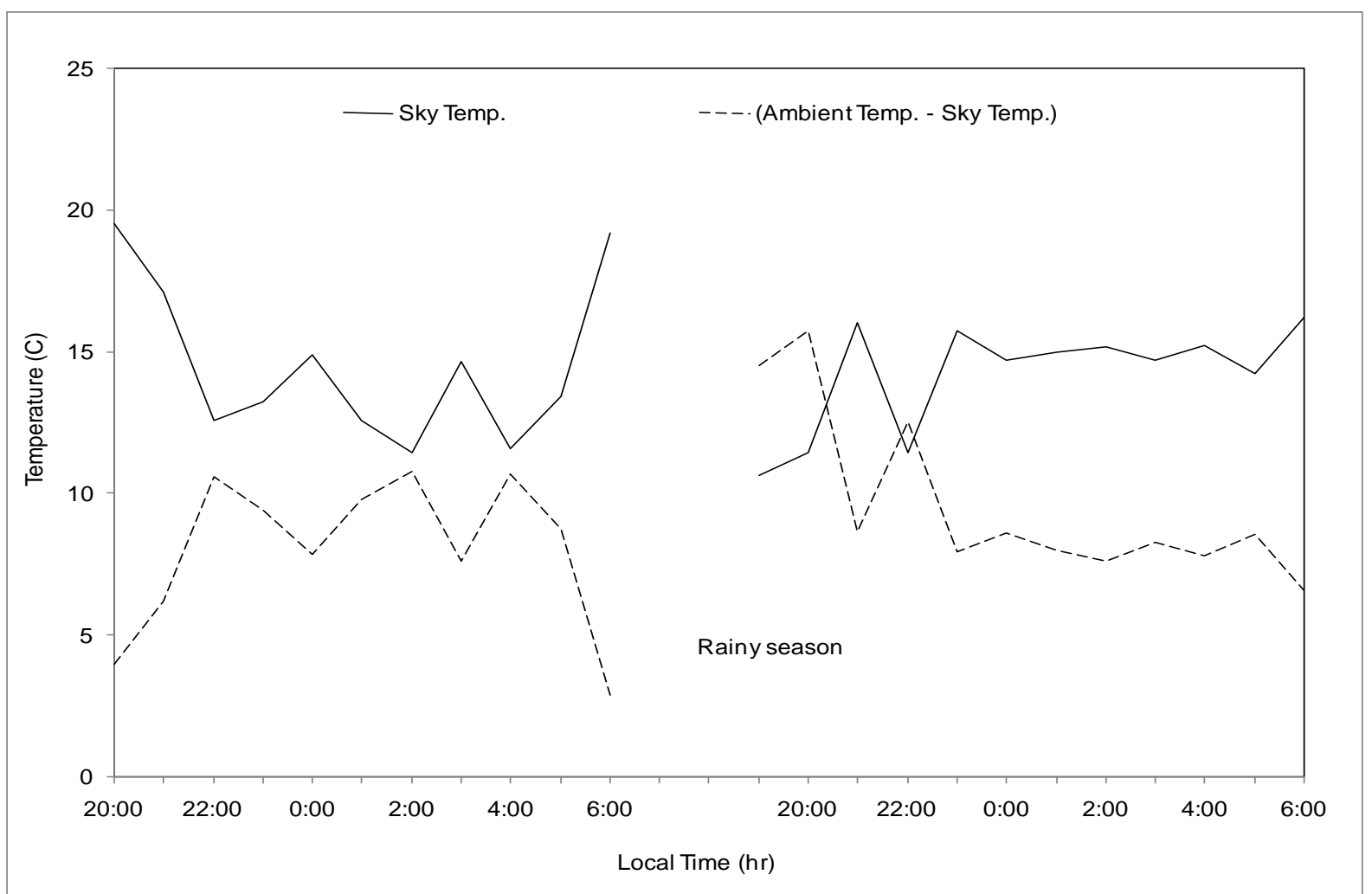

Fig. 5 The night sky temperature and its depression below ambient temperature during the rainy season.

\section{Conclusion}

Measurements to experimentally determine the long wave night sky radiation in Owerri, a tropical south eastern city in Nigeria, have been conducted. Measurements were taken at periods of the year representative of the three major climatic conditions of this city. Based on the results obtained after analysis of data collected, the following conclusions may be drawn. 


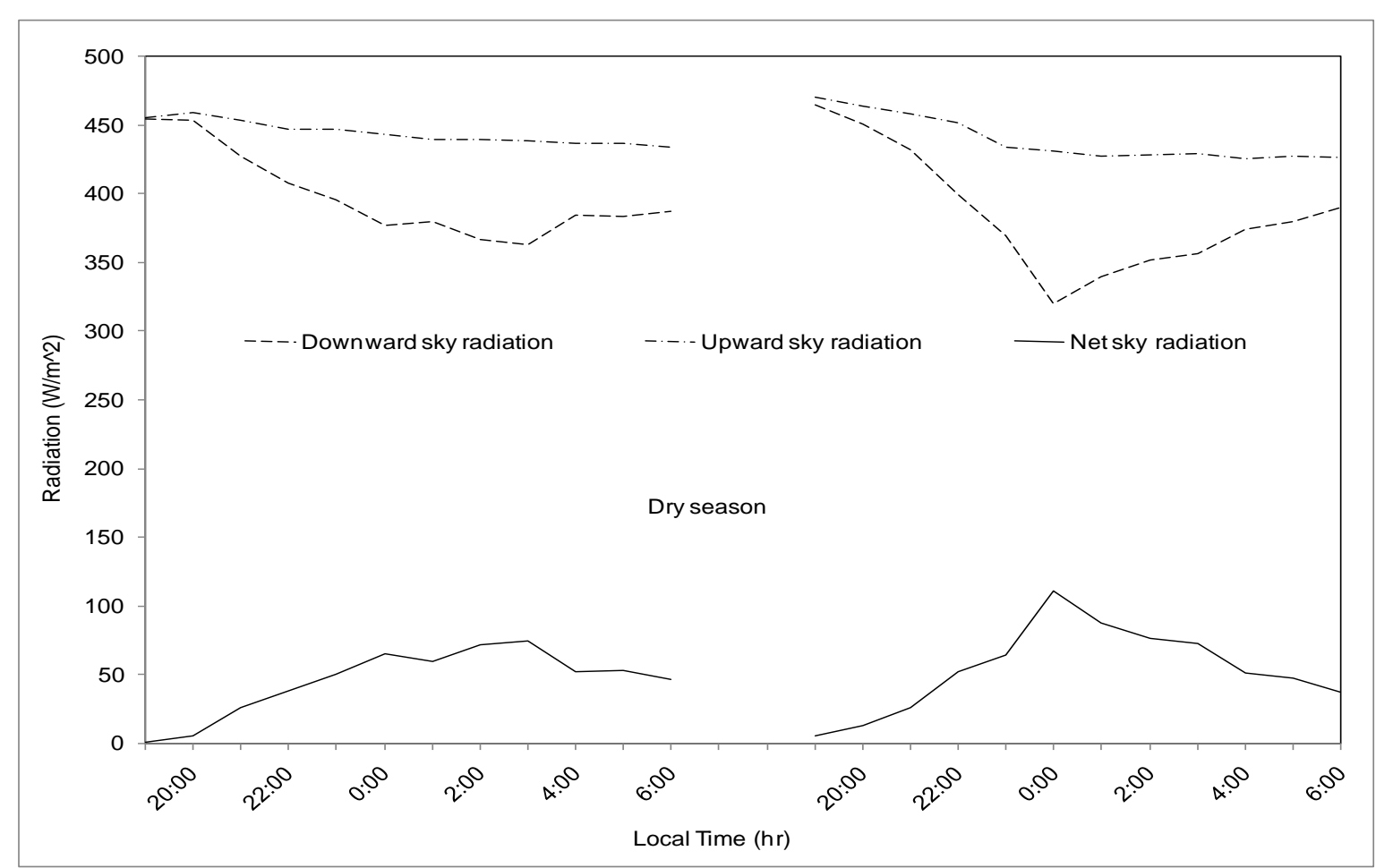

Fig. 6 The night sky radiation at the location during the dry season.

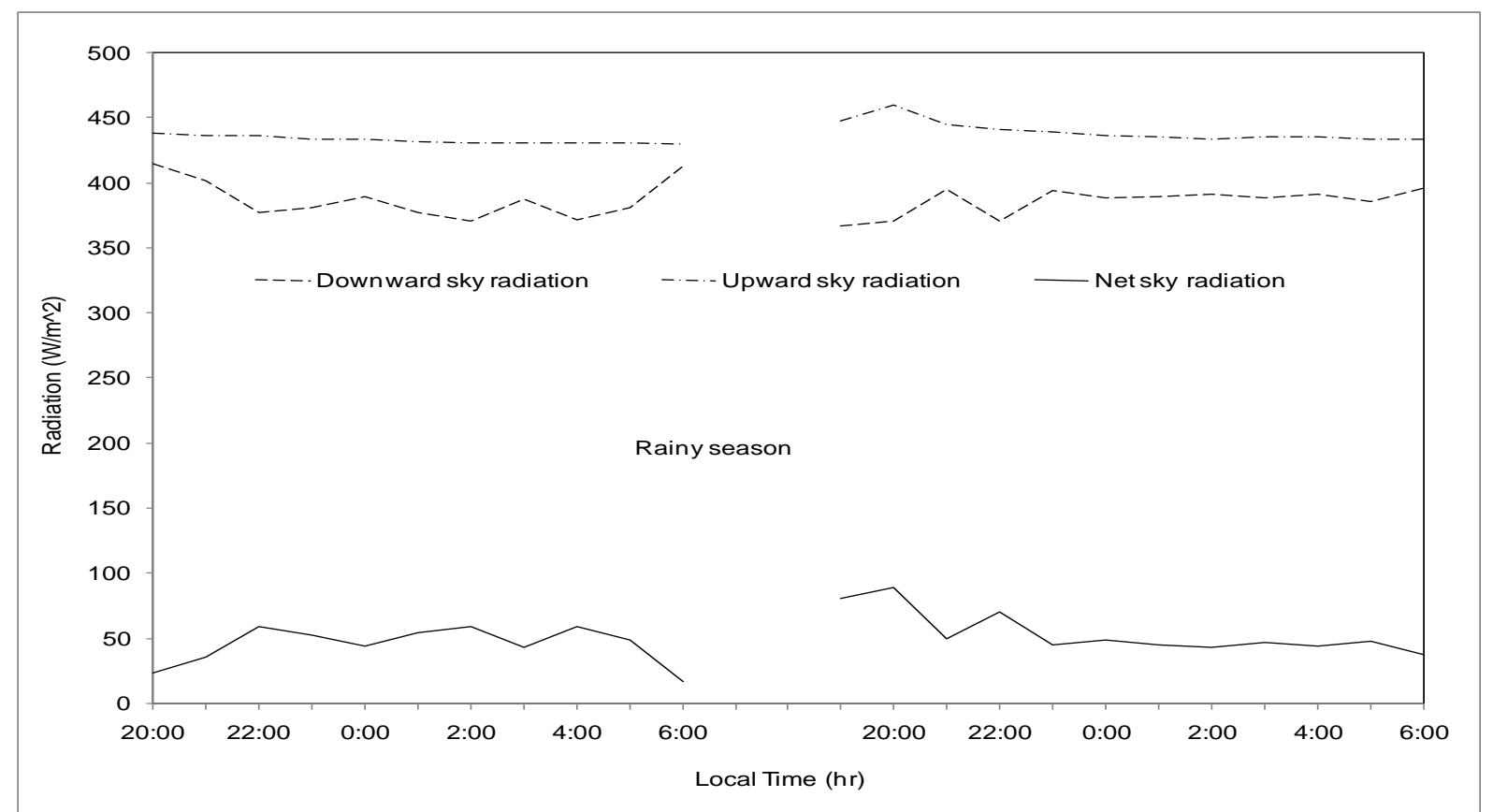

Fig. 7 The night sky radiation at the location during the rainy season.

i.) The net radiation to sky of up to $130 \mathrm{~W} / \mathrm{m}^{2}$ is possible depending on time of day and period of the year. Overall, an average value of about $66 \mathrm{~W} / \mathrm{m}^{2}$ is possible.

ii.) The dry season presented better potential for space cooling using the night sky radiation. Fortunately, this is the period of year when comfort is desired most.

\section{References}

[1] Ezekwe, C.I. (1986). Nocturnal radiation measurements in Nigeria. Solar Energy 37(1), pp. $1-6$. 
[2] Angstrom, A. (1913). An International Review of Spectroscopy and Astronomical Physics.The Astrophysical Journal, Vol. 37, pp305-317.

[3] Maurer, J. (1887). Measurement of Nocturnal Radiation. Annales de Chime at de Physique, Vol. 20, pp 204-220.

[4] Armenta-Déu, C., Donaire, T. and Hernando, J. (2003). Thermal analysis of a prototype to determine radiative cooling thermal balance. Renewable Energy 28, pp. 1105 - 1120.

[5] Cheikh, H.B. and Bouchair, A. (2004). Passive cooling by evapo-reflective roof for hot dry climates. Renewable Energy 29, pp. 1877 - 1886.

[6] Khedari, J., Waewsak, J., Thepa, S. and Hirunlabh, J. (2000). Field investigation of night radiation cooling under tropical climate. Renewable Energy 20, pp. 183 - 193.

[7] Bagiorgas, H.S. and Mihalakakou, G. (2008). Experimental and theoretical investigation of a nocturnal radiator for space cooling. Renewable Energy 33, pp. 1220 - 1227.

[8] Dimoudi, A. and Androutsopoulos, A. (2006). The cooling performance of a radiator based roof component. Solar Energy 80, pp. 1039 - 1047.

\section{Acknowledgement}

The authors gracefully acknowledge the financial support of the World Bank under its STEPB research grant for renewable energy research in the Federal University of Technology, Owerri, Nigeria. 